\title{
The role of gender in the formation of Anglo-American legal terminology
}

\author{
Elena Volgina $^{1}{ }^{*}$, Elena Ilyicheva ${ }^{1}$, Elina Kalinichenko $^{2}$, Anna Lanina ${ }^{2}$, and Victoria Polyakova $^{3}$ \\ ${ }^{1}$ Saratov State Law Academy, 1, Volskaya street, 410056, Saratov, Russia \\ ${ }^{2}$ Saratov State Agricultural University n. a. N.I. Vavilov, 1, Theatralnaya Square, 410012, Saratov, Russia \\ ${ }^{3}$ Saratov Socio-Economic Institute (branch) of Plekhanov Russian University of Economics, Radischeva 89, 410003 Saratov, Russia
}

\begin{abstract}
The various elements of the gender system have an impact on specialized areas of the language. Legal terminology is no exception, since the law covers almost all spheres of society. The interdisciplinary nature of gender studies has led to the demand for linguistic competence to study the gender construct, which has given rise to an independent discipline - linguistic genderology. In this regard, the problem of the influence of extralinguistic factors on the formation of legal terminology is relevant. In this paper linguistic research is conducted, within the framework of which Anglo-American legal terminology and its formation under the influence of gender factors are considered. The role of extra-linguistic factors in the formation of legal terms has been determined, the extra-linguistic factors affecting the gender markedness of the form and content of legal concepts have been identified. The method of continuous viewing of English legal texts, as well as English legal dictionaries, revealed gender-marked English-American legal terms and terminological concepts. The result of the study was the definition of a gender factor as a backbone for the Anglo-American legal terminology.
\end{abstract}

\section{Introduction}

For modern linguistics, the research paradigm, based on the principle of anthropocentrism in the study of linguistic phenomena, which is expressed in an attempt to comprehend them through the prism of a human, continues to be relevant [1-4].

The individual characteristics of a linguistic personality come to the fore when studying a person in a language, the most important of which is gender, which determines its social, cultural and cognitive orientation in the world. Gender issues are the focus of one of the central areas of human science called "gender studies". The interdisciplinary nature of such studies has led to the demand for linguistic competence to study the gender construct, which has given rise to an independent discipline - linguistic genderology. In our study, we adhere to linguistic and sociolinguistic approaches to the understanding of gender linguistics, as it is important for us, on the one hand, to consider the possibility of language in representing gender-marked legal concepts, on the other hand, the sociolinguistic justification of the influence of gender factors on the formation of legal terminology.

The central concept of genderology is gender. It is unproductive to give an unambiguous definition of this term, since it is a multifaceted phenomenon. Within the framework of gender studies, the term gender is understood as a system of differences structured under the influence of culture. It is in some way related to, but not limited to, biological differences. Gender does not reflect fixed, natural physical differences between men and women, but rather gender is knowledge that establishes values for bodily differences, as these differences vary across cultures, social groups, and time. Thus, two categories of differences - social and biological - are the basis of the concept of gender and are the theoretical basis for the consideration of legal concepts in the gender aspect. In this regard, gender is considered as a socio-cultural construct; it is interpreted as a conventional phenomenon; it is considered as a discursive factor of variable intensity.

In this paper, the legal terminology is understood as a set of legal terms related to the concepts of branches of law. A legal term is a word or phrase expressing a certain concept of law.

The purpose of the work is to determine the role of extralinguistic factors in the formation of legal terms. Related to this is the relevance of this article, which is determined by the study of the influence of gender factors on the structure and content of Anglo-American legal concepts.

The gender approach to the study of Anglo-American legal terminology allowed us to trace the relationship between the gender system of society and law, which is reflected in the structure, semantics and functioning of legal terms. This approach has also made it possible to substantiate the existence of gender legal concepts. To consider the legal terminology in gender aspect, such methods as component analysis, contextual analysis,

\footnotetext{
Corresponding author: saratov-79@list.ru
} 
analysis by direct components, cognitive-discursive analysis were used. An integrated approach to the study of legal terminology will reveal the degree of influence of gender factors on the formation of legal terminology and legal concepts.

By the method of continuous review of English legal texts, as well as legal dictionaries, we have identified gender-marked English terms of law. Terms that are not fixed by existing dictionaries (mainly neologisms or multicomponent terms) are distinguished from written sources (legal acts and special legal literature) based on their function of naming special concepts of law in the text. Gender-marked is a term that has an indication of gender in its structure, or in its conceptual content, or in its context implementation. At the same time, gender is understood by us as a socio-cultural construct, since the phenomena of masculinity and femininity can be considered not only as a natural given, but as dynamic, changeable products of human society, subject to social modeling. Therefore, the gender system is the institutions, behaviours and social interactions that are prescribed according to gender.

\section{Results and Discussion}

Extralinguistic conditionality of the law terminology implies the analysis of socio-cultural factors that influence the understanding of masculine and feminine aspects of behavior in the Anglo-American society and, to an indirect extent, the perception of superstructural terminological systems $[5,6]$. Many scientists point to the connection of legal terms with cultural traditions and with the social life phenomena [7-14]. According to A. Sarat and V. Felstiner, there is an interplay between law and social reality [15]. Feminism is the most important factor that changes traditional ideas about men and women.

Feminist researchers have repeatedly pointed to the ability of legal institutions to define, delineate the activities and identity of women, both in the public and private spheres [13]. Examples include restrictions on working hours (women's working hours), different retirement age for men and women. Nevertheless, it must be recognized that there are biological factors (associated with pregnancy, recovery period after childbirth), which worsens the chances of women in the labor market.

One of the goals of legal research is to bring legislation in line with the needs of social reality. The way the law exists as a form of law is language. The choice of nominative means is determined by the specificity of the field of knowledge under consideration, namely the desire to observe gender equality. The concept and its nominating term receive a certain address, fit into a certain coordinate system. A new term makes it possible to better understand the patterns of formation of terminology systems taking into account gender factors.

When considering the reflection of the dynamics of the gender system in the meanings of legal terms, two main mechanisms of gender increments were identified - the generalization and specification of the terminological meaning.

The gender system is a static phenomenon, in turn, the social construction of the gender system is a dynamic process that makes changes in it. In this regard, there are various changes in the semantics of terms. The generalization of the meaning of the terms is evidenced by the various comments to the terminological definitions, which constitute a generalized definition. The American term alimony has the following definition: "Alimony or separate maintenance payments are amounts paid by one spouse to another in discharge of the paying spouse's obligation under local law to support the other spouse" [16]. The comment follows: "Generally, it has been the husband who has been ordered to support his wife but under some modern statutes the wife could be ordered to support a husband if he were in actual need. Indeed, statutes which have gender-based standards for awarding alimony have been found to be unconstitutional as a violation of equal protection" [16]. The change of gender stereotypes is the reason for the modification of definitions and, consequently, legal terminology meanings.

The generalization of the meaning of terms is the result of the neutralization of the gender factor influencing the interpretation of the concept. For example, the term widow's benefit - "a benefit formerly payable to widows" - changed its form to bereavement benefit - "a benefit payable to widows and widowers" [16]. Thus, the definition eliminates the reference to the unequal distribution of financial payments. The international legal documents on human rights (human rights) and the implementation of this concept in relation to women (women's human rights) - especially the concept of the UN Convention on elimination of all forms of discrimination against women - play a significant role in establishing the legal status of the problem of gender equality. However, gender-neutral legislation does not take into account the social realities of a gender-based society, in particular, the reproductive role of women, which places women in an unequal position in the labour market. Such legislation provides only formal equality of rights, eliminating some social barriers for women.

Within the group of terms under consideration, we can talk about such entities, the structure of which does not contain references to gender, but which are related to gender by the specifics related to these individuals, such as their field of activity, occupation, etc. The phenomenon designated by a particular term can be gender-specific and occur in most cases with one of the sexes (men or women). Legal terminology fixes this gender specificity, which is expressed in the specification of the meaning of the term. This phenomenon can be considered using the term selfdefense as an example. Self-defense is considered a masculine method of protection (male-oriented defense), as this method is used at the time of the attack (i.e., involves physical force). In this case, the physical characteristics of men and women who react differently to violence are not taken into account. In this regard, lawyers advocate the introduction of a new term to refer 
to the method of protection that the victim may use not at the time of causing physical harm to them, but as a result of constant violence. As such, the term defense of self-preservation is proposed - protection for the purpose of self-preservation, which can be used by both women and men, who as a result can be responsible for manslaughter, and not for felony. The law must take into account the different reactions of men and women in certain situations [16].

Certain types of crimes are committed more often against women, which also determines the presence, along with the gender-unmarked gender-marked meaning of the same term within the same terminological field. This phenomenon can be considered using the term violent disorder as an example. The term has the following definition: "An offence committed when three or more persons, present together, use or threaten unlawful violence" [16]. In a narrow sense, the seme indicating the sex of the object of action and its gender status is revealed: "It is also an office... to use violence towards or intimidate a person, his wife or children" [16]. This example points to the fact that the word person in this context refers not only to a man, but also to a husband. Thus, words that do not imply gender differences (such as a person) acquire a masculine connotation.

The terms may be gender neutral at the formal level, but have a gender-specific content. When specifying the gender, the lexical meanings of the terms are revealed in the definitions containing the words-markers, such as man, woman, male, female. For example, the term retirement age has the following definition - "the state pension age for men in the UK is 65 years and for women 60" [16].

The individual perception and description of any object or phenomenon is not rigidly determined, i.e. each situation can be differently described by linguistic means, since it is possible to use non-identical approaches to interpreting the situation and the different structural units of the nomination. Moreover, language is not only a means for transmitting and storing information, but also a tool with the help of which new concepts are formed that largely determine the style of thinking. The choice of specific language means influences the structure of thinking and thus the ways of reproducing reality.

Due to the fact that we consider the concept of gender as a discursive factor, legal discourse is important for us as a way of constructing gender meanings of legal terms. Discourse analysis of legal texts can be used in the study of legal terms, as the terms can not be limited to the description of linguistic forms, regardless of the purposes or functions for which they are used. Legal discourse reproduces and constructs gender practices existing in a given society. Therefore, the constructive role of legal discourse in structuring gender meanings of legal terms is important for us. Access to extralinguistic information is an additional, important source of knowledge about legal concepts.

The area of legal regulation of gender relations is, first of all, family law, within which the possibilities for the construction of family roles are especially great because of its notorious uncertainty and the lack of clear standards [12].

In most cases, the presence of several terms to refer to the same objects, subjects, phenomena, and processes, is due to the need for a certain nuance, acquiring from a pragmatic point of view of fundamental importance. If the parent does not conform to traditional gender roles, new legal categories are created or existing categories are expanded to clarify the status of these parents.

The object of legal regulation are the legal rights and obligations of parents. Due to the fact that the roles of mother and father in raising a child are associated with social stereotypes and are perceived by society in different ways, the gender asymmetry of the social aspect of parenting has been revealed. The actual gender asymmetry in the distribution of responsibilities for the maintenance and upbringing of the child is an urgent problem. The existence of the term rendering of child care suggests that child care is the prerogative of the mother, not the father. Under English law, the court does not always order a paternity test, as this may not be in the best interests of the child. The court may therefore order the alleged father (to force the putative father) to provide financial support (to maintain the child) [16]. Under American law, the question of paternity (paternity disputes) is decided by the court before the amount of payments is established.

Modern advances in medical technology enable people who cannot have children to give birth to children in an artificial way. The possibility of artificial insemination (human assisted reproduction) means that you can not base the concept of parenthood (parentage) only on genetic relationships. Concepts of the genetic father / genetic mother, donor, surrogate mother designate parents, who are such only relative to a biological fact, i.e. they give birth to a child, but do not participate in their upbringing, thereby breaking the stereotype about the traditional roles of mother and father. Moreover, if the parent voluntarily abandons the unborn child to be raised by social parents, the rights of the biological father will differ from the rights of the biological mother to the child. The definitions of the terms legal father and legal mother indicate the asymmetric relation of the law to the donor father and surrogate mother: "The legal father is generally the genetic father except when the latter is a donor" [16]; "The legal mother is a woman who has given birth to the child, regardless of genetic parentage" [16]. Unlike the donor, the surrogate mother has rights to the child. The verbal form of these terms also explicates a different status of a surrogate mother and donor: surrogate mother, donor, where the latter term is not aspectual to the term father.

Despite the fact that artificial insemination (artificial insemination of the donor) is widespread and accepted by society, for many people this practice is associated with moral and legal difficulties. For example, $\mathrm{K}$. Richman cites the example of the case of the award of rights of custody over the child to the donor. The judge did not satisfy the claim (rejected a donor's paternity claim), arguing that the donor had not acted as a parent throughout the life of the child [13]. 
Artificial insemination can be seen by some people as a form of adultery. In order to prevent the occurrence of such difficulties, clinics do not disclose information about the identity of the donor, who is not the father by law. The birth of a child should correspond to the stereotypical scenario adopted in society. Social rejection of donation is determined by the artificial nature of this phenomenon, i.e. the term artificial contains such semes as 'not real', 'not made of natural things'. The law is involved in maintaining this stereotype. The legal discourse on artificial insemination touches upon the problematic aspects of this practice and the conflicts that it may entail.

We have previously said that the two categories of differences - biological and social - underlie the concept of gender and provide a theoretical basis for the consideration of legal concepts from a gender perspective. This is especially true for labor legislation. Due to the fact that women face discrimination in recruitment, when setting wages, the evaluation of gender equality is carried out by comparing her capabilities with his capabilities, i.e. the comparison is based on the male comparator (valid male comparator) the criterion for evaluating female labor is male labor, the terms of the female contract are compared with the terms of the male contract. The woman herself chooses the male comparator, after which she can demand equal pay. In this sense, the legal concept employment is gender-marked (gender-based), since it is male behavior in the labor market that is considered the norm and is taken as the basis for comparison. As a result, in the structure of the legal concept employment, we single out the conceptual feature of "equality of women to men", represented by the following terminological units: equal pay, equal pay during pregnancy and maternity, equality clause, like work, work of equal value, work rated equivalent, evaluation of the equality of work.

Today, many gender concepts have been operationalized into legal concepts and have become an integral part of the legal system. In this regard, the generic term gender participates in the formation of the whole terminological family of words: gender sexuality, gender inequities, gender reassignment, gender bias, gender discrimination, etc. For example, gender bias can be a legitimate cause of action in court. The study of the content of legal concepts within the framework of the cognitive paradigm of the analysis provided information on the differentiation of gender roles and the associated system of masculinity / femininity stereotypes in the legal sphere.

The study identified gender-marked legal terms, as well as terms that indirectly indicate gender. The semantics of legal terms in statics (dictionary definitions) and dynamics (legal discourse) was analyzed, which allowed us to identify the main ways of representation of the gender component in the structure and semantics of legal terms: the generalization and the specification of the meaning of the term.

The generalization of the meaning of the term indicates a tendency to reduce gender differences. The specification of the meaning of the term suggests that gender mainstreaming is relevant for a number of legal phenomena related to labour, criminal and family legislation.

The most productive way of gender representation in legal terminology is gender specification of meaning in the process of forming compound terms. This is due to the fact that gender is sometimes implicitly represented in legal terminology and its explication often occurs through the formation of specific concepts.

The result of the study is that gender is not only a significant parameter of the nomination process in the field of legal terminology of the English language, but also an important factor in the development of the terminological system of law as a whole.

\section{Conclusion}

The analysis of the terminology of law clearly shows the picture of gender refraction at the linguistic and conceptual levels. Thus, it would be legitimate to consider gender as one of the determining factors influencing the formation of legal terminology.

Being formed as gender neutral, asserting the principles of gender equality, the law, at the same time, cannot ignore the existing gender system and stop the constant process of constructing gender reality. In this regard, it can be argued that the terminology of law is formed and operates under the influence of gender. As a result of the study, extralinguistic reasons affecting the structure and functioning of a legal term were identified:

- specificity of legal terminology as a social superstructure that accumulates gender stereotypes associated with the biosocial nature of men and women;

- the existing system of gender relations in society, which forms asymmetric social ideas about masculinity and femininity and which is reproduced in daily practices of communication, behavior and supported by social institutions, as well as legal discourse, determines the linguistic variation of the terms of law;

- despite changes in the gender system in modern Western society, there is actual inequality of women, whose reproductive role determines their particular representative interest in family and labor laws, which is reflected in terminological designations, in the legal terminological system, as well as in the conceptualization of legal notions;

- the law takes into account the gender specifics of a number of crimes, which determines the composition of aspectual polyverbs and the definition of legal terms.

The analysis of legal terms from a gender perspective can be considered a promising area of legal linguistics. On the basis of the obtained data it is possible to study the gender nature of legal terminology systems of other languages. Of particular interest is the study of socially oriented terminology (sociological, economic) in order to identify the role of gender in the formation of terms, which will also allow identifying tendencies in the development of the gender system of society as a whole. 


\section{References}

1. Superanskaya A V, Podolskaya N V, Vasilyeva N V 2012 General terminology: Theory issues (Moscow: Librokom)

2. Morova O L 2017 Pragmatic potential of the means of speech contact Language and the world of the studied language ed A Zaraysky (Saratov: Saratov Social and Economic Institute) chapter 8 pp 75-79

3. Manerko L A 2018 Cognitive terminology as a reflection of the anthropocentric and constructive view of terminological systems and special discourse Cognitive language studies $\mathbf{3 4} 720$

4. Khizhnyak S P 2016 Cognitive and traditional terminology Russian language and literature in the educational process ed O Avdevnina (Saratov: Publishing House «Mark») pp. 94-100

5. Danilov K V 2017 Differentiation of the British and American concept CRIME (on the material of legal terminology) Language - communication education: research methodology and teaching practice ed E Balashova (Saratov: IP Koval Ju.V.) pp. 35-37

6. Khizhnyak S P 2017 The ratio of naive and scientific legal pictures of the world News of higher educational institutions 2 (42) 88

7. Khizhnyak S P 2015 Legal picture of the world as a basis for studying the specifics of the legal culture of different countries and foreign languages Bulletin of the Saratov State Law Academy 5 (106) 212
8. Leychik V M 2009 Terminology: the subject, methods, structure (Moscow: Librokom)

9. Kuznetsova Yu A 2017 The concept of "LAW" in the scientific legal and everyday worldview of the world of the English language Language world of the studied language ed A Zaraysky (Saratov: Saratov Social and Economic Institute) pp. 61-66

10. Kharitonova V.Yu 2008 Frame and categorical organization of the euphemistically objectified concept of THEFT Bulletin of the Chelyabinsk State Pedagogical University 3275

11. Timofeeva N P 2016 On the nature of the evaluation of terminological concepts Language. Socium Culture ed A Zaraysky (Saratov: Saratov Social and Economic Institute) pp. 54-58

12. Richman K L 2002 Legal Strangers, and Parents: Negotiating Parental and Sexual Identity in Family Law Law and Society Association (36) 2285

13. Kaganas F, Diduck A 2004 Incomplete Citizens: Changing Images of Post-Separation Children The Modern Law Review (67) 6959

14. Rollins J 2002 AIDS, Law, and the Rhetoric of Sexuality The Journal of the Law and Society Association (36) 1161

15. Sarat A, Felstiner A 1995 Divorce Lawyers and Their Clients: Power and Meaning in the Legal Process (New York: Oxford Univ. Press)

16. Martin E A 2003 Dictionary of Law (Oxford: Oxford Univ. Press) 